\title{
BINARY PATTERN GENERATION OF POETIC ORDER IN SANSKRIT POETIC METERS.
}

\author{
Ms. Meena Kumar ${ }^{1 *}$,Dr. C.S.Warnekar ${ }^{2}$, Mr.Saurabh Saxena. \\ ${ }^{1}$ Assistant Professor, D.I.R.D (GGsipu), Delhi (India) \\ ${ }^{2}$ Former Principal, Cummins College, Pune (India) \\ ${ }^{3}$ Assistant Professor, D.I.R.D (GGsipu), Delhi (India)
}

*Corresponding Author: -

\begin{abstract}
: -
The Pattern generation and Analysis is the technique of recognizing an object say, a target in combat space. The combat space $T$ consists of targets of three types

i) Wanted Targets $W$ ii) Rejected Targets $R$ iii) Unknown Targets $U$

$$
\text { So that } T=W \cup R \cup U
$$

The description of object is called pattern.Charaterization of pattern class by common properties shared by all of its members is another basic concept used in design of an pattern recognisation system. Main objective of this approach is to determine common properties from finite set of samples patterns and to examine a new pattern for a suitable switch. In signal processing, the role of input is vital to recognize objects. The input to the digital computer refers to any data or instructions entered into the memory. Data is a set of meaningful perceptual observations about an entity expressed in numerical, alphabetical, graphical or mixed form. While Instructions refer to a set of action commands issued to CPU to tell a computer how to perform the tasks necessary to process data into information. Digital computer can accept the input via written/typed form through keyboard or the spoken/audio form through microphone. A great deal of work has been done in evaluating speech as a means of computer input. The present paper suggests the rhythmic syllable arrangements in various poetic meters as a means of audio input, directly producing binary code. Such binary syllable arrangement has been envisaged by Pingalacharya [1]. His Chhandas Shastra or science of poetic meters in Sanskrit is a well known classical treatise on Prosody. It deals with the rhythmic syllable arrangements in various poetic meters. According to Chhandas Shastra [2] every pronounced letter is either "Laghu” or Short [0] and "Guru” or Long[1] and each poetic meter is based on their fixed sequence[3]. Hence desired binary input sequence could be produced merely by utterance of corresponding syllables. Case studies of over 15 sets of such voice samples by male/female/child candidates were conducted and the resulting binary sequences are presented with corresponding accuracies.
\end{abstract}

Keywords: - Combat space, Frequency-domain, Patterns, Time-domain, Thresholding.

\section{(다)( $($ (1)}




\section{INTRODUCTION}

The science of Sanskrit poetics [5] describes well developed encoding mechanism for phonetic-meters. The phoneme[6] can be described as the smallest segmental unit of sound employed to form meaningful contrasts between utterances of any language syllables. It is regarded as an abstraction of a set of speech sounds (phones) which are perceived as equivalent to each other in that language. Such phonetic order holds special importance in poetry, as it differentiates between various poetic meters. The Chhandas Shastra or science of poetic meters in Sanskrit as envisaged by Pingalacharya [1] is a well known classical treatise on Prosody. It deals with the rhythmic syllable arrangements in various poetic meters. According to Chhandas Shastra [2] every pronounced letter is either

"Laghu" or Short and "Guru" or Long and each poetic meter is based on their fixed sequence[3]. Such sequence is symbolically represented by 'S' for long and 'I' for short syllable in classical Sanskrit literature. Replacing S (long) by 1 and I (Short) by 0 results in binary sequence corresponding to a poetic meter which can be identified using standard pattern recognition methods [4]. The science of Sanskrit poetics [5] describes well developed encoding mechanism for phonetic-meters. The phoneme [6] can be described as the smallest segmental unit of sound employed to form meaningful contrasts between utterances of any language syllables. It is regarded as an abstraction of a set of speech sounds (phones) which are perceived as equivalent to each other in that language. Such phonetic order holds special importance in poetry, as it differentiates between various poetic meters. Pingalacharya grouped three syllables as triplets according to their long- short combinations in 8 possible permutations. The striking esemblance with corresponding 3 bit binary sequence may be noticed as follows:

\begin{tabular}{|c|c|c|c|c|c|}
\hline Sr.No & $\begin{array}{c}\text { Long } \\
(\mathbf{L}) / \\
\text { Short } \\
(\mathbf{H}) \\
\end{array}$ & $\begin{array}{c}\text { Classical Symbolic } \\
\text { Representation }\end{array}$ & $\begin{array}{c}\text { Binary } \\
\text { equivalent }\end{array}$ & $\begin{array}{c}\text { Gana-Symbol } \\
\text { Sanskritmnemonic }\end{array}$ & $\begin{array}{l}\text { English } \\
\text { Equivalent }\end{array}$ \\
\hline 1 & LLL & SSS & 000 & na-gana & Tribrachys \\
\hline 2 & LLH & SSI & 001 & ta-gana & $\begin{array}{c}\text { Anti- } \\
\text { bacchius }\end{array}$ \\
\hline 3 & LHL & SIS & 010 & ra-gana & Amphimacer \\
\hline 4 & LHH & SIl & 011 & bha-gana & Dactylus \\
\hline 5 & HLL & ISS & 100 & ya-gana & Bacchius \\
\hline 6 & HLH & ISI & 101 & ja-gana & Amphibrachy \\
\hline 7 & HHL & llS & 110 & sa-gana & Anapaestus \\
\hline 8 & НHН & LII & 111 & ma-gana & Molussus \\
\hline
\end{tabular}

The method of identifying a short or long syllable is simple. A syllable can be short (laghu) or long (guru) according to whether its vowel itself is short or long. Also, a short vowel can become long when it is followed by anusvaaram (am) or visargam $(\mathrm{aH})$. Moreover, if a conjunct consonant (i.e, a half consonant, one that is not attached to any vowel - called samyuktaakShara in Sanskrit)[8] follows a short or a long vowel, the whole syllable is considered Long. The present paper carries out such identifications of phonetic meters by standard binary pattern recognition process. A binary tree to categorize phonetic input into long and short syllables is described here. Initially all the syllables are assumed to be Short thus producing binary sequence of all 0 's. Next the six tests for determining Long syllable are applied sequentially and accordingly the 0 's in the binary sequence are changed to 1's. This produces the correct binary sequence for the corresponding poetic meter which is then identified by pattern recognition method. One of the most basic measurements in perception is the measurement of threshold. The threshold measureshow strong a stimulus must be before it can be detected or how different two stimuli must be before they can bediscriminated from one another. Thresholds are of interest for several reasons. Threshold measurements are often used to reason about the nature of sensory processing.Audio signal processing,sometimes referred to as audio processing, is the intentional alteration of auditory signals, or sound, often through an audio effect or effects unit. As audio signals may be electronically represented in either digital or analog format, signal processing may occur in either domain. Analog processors operate directly on the electrical signal, while digital processors operate mathematically on the digital representation of that signal. Audio signals are sound waveslongitudinal waves which travel through air, consisting of compressions and rarefactions.

\section{Identifying The Syllable Sequence: -}

The method of identifying a short or long syllable(in phonetically based any Indian language) is simple. A syllable can be short (laghu i.e 0) or long (guru i.e. 1) according to whether its vowel itself is short or long. Alternatively, a short vowel can become long when it is followed by anusvaaram $(\mathrm{am})$ or visargah $(\mathrm{aH})$. Moreover, if a conjunct consonant (i.e. a half consonant, one that is not attached to any vowel - called samyuktaakshara in Sanskrit)[8] follows a short vowel, the previous syllable is considered Long. The present paper extends the method of such identifications of phonetic meters by standard binary pattern recognition process. A binary tree to categorize phonetic input into long and short syllables is 
described here. Initially all the syllables are assumed to be Short thus producing binary sequence of all 0's. Next the six tests for determining Long syllable are applied sequentially and accordingly the 0's in the binary sequence are changed to 1 's. This produces the correct binary sequence for the corresponding poetic meter which is then identified by pattern recognition method.

The syllable arrangement is recorded and represented visually as a waveform. Here is a waveform of a spoken phrase. Note the frequent changes in wavelength, amplitude, and frequency.

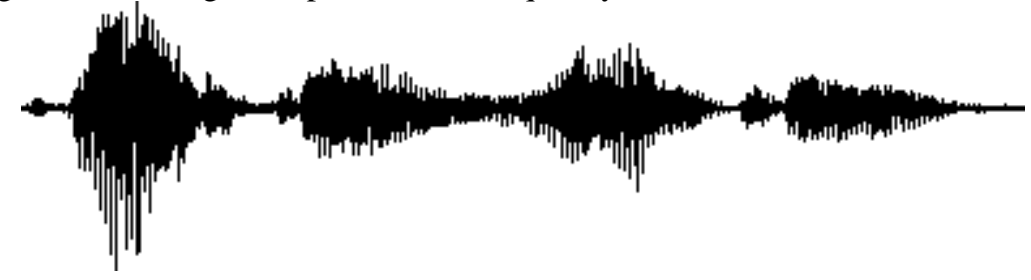

\section{Waveform of a spoken phrase.}

Quantization, analog-to-digital conversion and thresholding are carried out to generate the binary sequence. The wave files are converted and stored as binary numbers using MATLAB function in a bit file.

\section{Procedure And Experimental Set Up :}

A standard high quality audio recording system is set up to record selected groups of syllable arrangements pronounced by number of candidates drawn from male, female, children, young and old persons. They are asked to repeat same group of syllable which are recorded via audio system to form the audio file .Digital Audio recording technology encode an audio signal in digital form via an analog to digital converter (ADC)[9]. The pronounced syllables are made available in data files by the system. An audio file format [11] stores digital audio data on a computer system. Raw Bit-Stream format is also available in this file which is used as input to our system.

\section{What is digital sound data?}

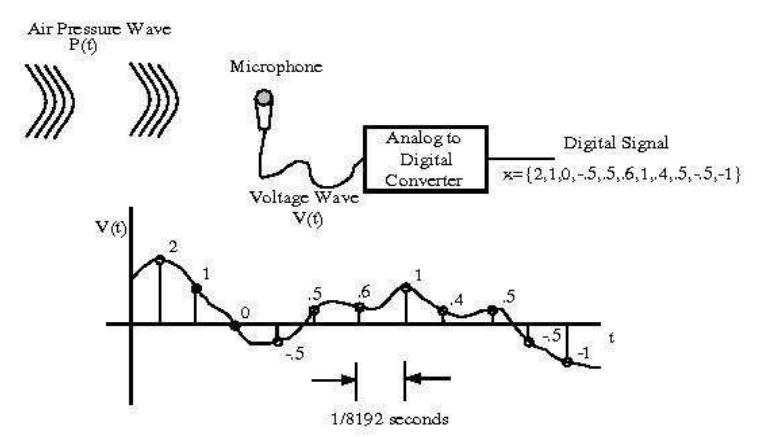

\section{Experimental Work :}

This picture shows where the signal corresponds to Long and Short syllable over time. Time Domain representations of Sound Waveforms are as follows:-.
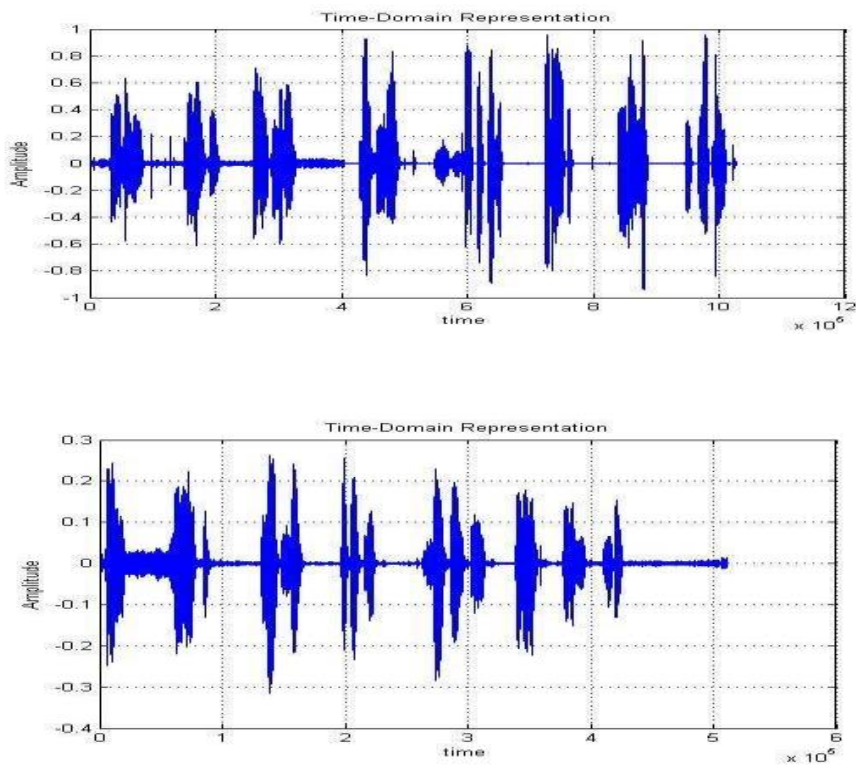


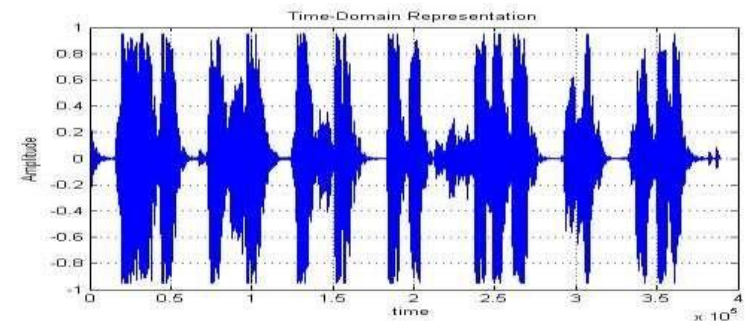

Time Domain Representations of Training Samples

From the number of phonetic samples collected from over 15 candidates ,the sequence of LAGHU or SHORT(0) and GURU or LONG(1) was generated using MATLAB wave function. The result of thresholding of the waveforms or two out of 15 samples is as follows:-

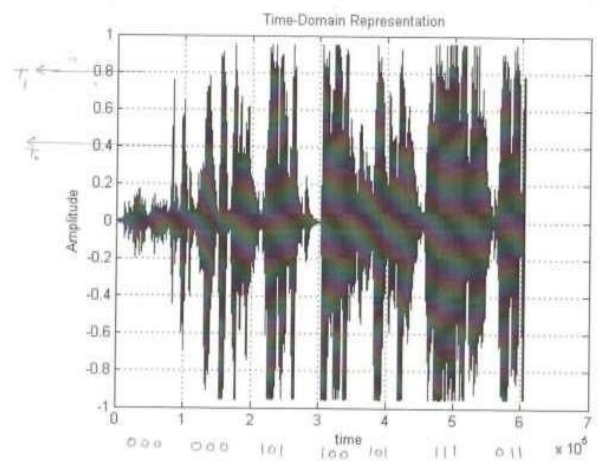

The corresponding binary sequences resulting from the thresholding of above waveforms are given in the following table $:-$

\begin{tabular}{|c|c|c|c|c|c|c|c|c|}
\hline Sample & $\begin{array}{l}\text { Word } \\
1 \\
\end{array}$ & $\begin{array}{l}\text { Word } \\
2 \\
\end{array}$ & $\begin{array}{l}\text { Word } \\
\mathbf{3} \\
\end{array}$ & $\begin{array}{l}\text { Word } \\
4 \\
\end{array}$ & $\begin{array}{l}\text { Word } \\
5 \\
\end{array}$ & $\begin{array}{l}\text { Word } \\
6 \\
\end{array}$ & Word7 & $\begin{array}{l}\text { Word } \\
8 \\
\end{array}$ \\
\hline 1 & 000 & 100 & 101 & 000 & 100 & 000 & 000 & 111 \\
\hline 2 & 000 & 001 & 010 & 011 & 100 & 101 & 110 & 111 \\
\hline 3 & 000 & 000 & 101 & 100 & 101 & 111 & 011 & 111 \\
\hline 4 & 000 & 000 & 000 & 101 & 110 & 110 & 011 & 011 \\
\hline 5 & 000 & 100 & 101 & 000 & 100 & 000 & 000 & 111 \\
\hline 6 & 000 & 001 & 010 & 011 & 100 & 101 & 110 & 111 \\
\hline 7 & 000 & 000 & 101 & 100 & 101 & 111 & 011 & 111 \\
\hline 8 & 000 & 000 & 101 & 100 & 101 & 111 & 011 & 111 \\
\hline 9 & 000 & 100 & 101 & 000 & 100 & 000 & 000 & 111 \\
\hline 10 & 000 & 001 & 010 & 011 & 100 & 101 & 110 & 111 \\
\hline 11 & $\mathbf{0 0 0}$ & 000 & 101 & 100 & 101 & 111 & 011 & 111 \\
\hline 12 & 000 & 001 & 010 & 011 & 100 & 101 & 110 & 111 \\
\hline 13 & 000 & 100 & 101 & 000 & 100 & 000 & 000 & 111 \\
\hline 14 & 000 & 001 & 010 & 011 & 100 & 101 & 110 & 111 \\
\hline 15 & 000 & 001 & 010 & 011 & 100 & 101 & 110 & 111 \\
\hline
\end{tabular}

Binary sequences resulting from the thresholding of waveforms

\section{Results and Conclusions:}

From the above experiment a pattern of 0 and 1 waveform was created by applying the suitable Threshold. Recording mechanism, training samples, Phonetic signatures, Generelized envelope for syllable and thresholding are the the important parameters which decides the accuracy of produced binary code. Though the overall accuracy is somewhat low due to low grade audio recording ,it attempts to establish the basic idea of providing audio input via rhythmic syllable arrangement. From the above table it is found that pattern of 0 and 1 waveform was created by applying the suitable Threshold. These binary sequences for all the samples were almost same whether it is pronounced by male, female, child or elder person, making speaker independent phonetic input for the our machine. 


\section{Future Scope:}

Besides, the mathematical interpretations of science of poetic meters, given by Halaayudha, report evaluation of various variants of patterns of binary sequences which bear striking resemblance with schema and fitness function of Genetic Algorithms[10][13]. It is well known that Genetic algorithmis a search technique used in computing to find possibly an exact or approximate solution to multi-parameter optimization problems. It was purposed and developed in 1960 by John Holland at university of Michigan. The critical comparative study initiated in the present paper suggests that there is scope to carry out innovative research \& development through suitable amalgamation of the two fields.

\section{Nomenclature \\ L Laghu \\ G Guru \\ O Short \\ $1 \quad$ Long}

References: -

[1].Brown, Charles Philip (1869). Sanskrit prosody and numerical symbols explained. Trübner\&Co..byT.N.Rao And ShubhashKak

[2].Patwardhan, M. (1937), Chandoracana, Bombay: Karnataka Publishing House Jayadaman: a collection of ancient texts on Sanskrit prosody

[3].Varnashi.en.wikipedia.org/wiki/Pingala"computing Science in Ancient India "edited and a classical list of Sanskrit meters with an alphabetical index, Bombay:

[4].Vritratnakar byShriBhatkedwar Published by ChokhambhaPrakashaa. A Computational Algorithm based on Empirical Analysis, that Composes Sanskrit Poetry Meenalshi Laxmanana, Rama N (IJCSIS) International Journal of Computer Science and Information Security, Vol. 7, No. 2, 2010 A Computational Algorithm based on Empirical Analysis, that Composes Sanskrit Poetry.

[5].Vritratnakar by ShriBhatkedwar Published by Chokhambha Prakashan Varnashi. en.wikipedia.org/wiki/Pingala Sanskrit metre recognizer ("This is a test version. Only varNa-vRttas are now recognized.")

[6].B. van Nooten und G. Holland, Rig Veda, a metrically restored text, Department of Sanskrit and Indian Studies, Harvard University, Harvard University Press, Cambridge, Massachusetts and London, England, 1994.

[7].E.V. Arnold, Vedic metre in its historical development, Cambridge, UP, 1905.

[8]."computing Science in Ancient India "edited by T.N.Rao And Shubhash Kak

[9].Varnashi.en.wikipedia.org/wiki/Pingala“computing Science in Ancient India "edited

[10]. and a classical list of Sanskrit meters with an alphabetical index, Bombay:

[11]. VritratnakarbyShriBhatkedwar Published by ChokhambhaPrakashan

[12]. Vritratnakar by ShriBhatkedwar Published by Chokhambha Prakashan Varnashi.

[13]. en.wikipedia.org/wiki/Pingala

[14]. en.wikipedia.org/wiki/Vedic_meter

[15]. Friedrich Max Müller; Arthur Anthony Macdonell (1886), A Sanskrit grammar for beginners (2 ed.), Longmans, Green, p. 178PDF

[16]. Velankar, H.D. (1949), Jayadaman: a collection of ancient texts on Sanskrit prosody and a classical list of Sanskrit meters with an alphabetical index, Bombay: Haritoșamala

[17]. Weber, Albrecht (1863). Indische Studien. 8. Leipzig.

[18]. http://en.wikipedia.org/wiki/Vedas

[19]. Klaus Mylius, Geschichte der altindischen Literatur, Wiesbaden 1983. 